\title{
Characterization and Distribution of Flavonoids from Flowers in Different Horticultural Types of Begonia
}

\author{
Saffidine Karima ${ }^{1 *}$, Chirol Nadine ${ }^{2}$, Benayache Fadila ${ }^{3}$, Jay Maurice ${ }^{2}$
}

Saffidine Karima ${ }^{1 *}$, Chirol Nadine ${ }^{2}$, Benayache Fadila $^{3}$, Jay Maurice ${ }^{2}$ 'Department of Medicine, Faculty of Medicine, University Ferhat Abbas, Sétif, ALGERIA.

'Laboratory of Phytochemistry, University Claude Bernard-Lyon I, Villeurbanne, FRANCE.

${ }^{3}$ University Frères Mentouri Constantine 1, Constantine, ALGERIA.

Correspondence

Saffidine Karima

Department of Medicine Faculty of Medicine, University Ferhat Abbas, Sétif, ALGERIA.

Phone no: +21336503220

E-mail: safkarima@yahoo.fr

History

- Submission Date: 08-07-17.

- Review completed: 26-07-2017;

- Accepted Date: 22-08-2017.

DOI : 10.5530/pj.2017.6.133

Article Available online

http://www.phcogj.com/v9/i6

Copyright

(C) 2017 Phcog.Net. This is an openaccess article distributed under the terms of the Creative Commons Attribution 4.0 International license.

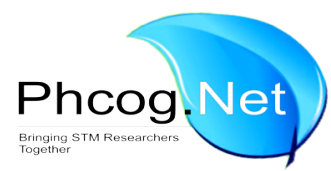

\begin{abstract}
Background: The begonias are ornamental plants known by the varied forms and colors of their flowers, as well as their decorative foliage. Objective: This study attempts to characterize the flavonoids isolated from flower extracts of different horticultural cultivars of the genus Begonia. Material and methods: The compounds of the ethyl acetate and aqueous extracts were separated by chromatographic methods and identified by UV spectra and chemical techniques. Results: The analysis allowed the characterization of flavonoids belonging to flavonol types in the free aglycones and glycoside forms of kaempferol and quercetin. On the other hand, fingerprinting analysis and quantification of major flavonoids of 184 cultivars were performed by high-performance liquid chromatography (HPLC). Among twenty five (25) components which were detected and separated: ten were corresponding to quercetin 3-Oglucosyl-rhamnoside (Rt=23.5), quercetin 3-O-glucoside ( $\mathrm{Rt}=25)$, kaempferol 3-O-glucosylrhamnoside and its acylated derivative $(R t=32)$, kaempferol 3-O-glucoside $(R t=33)$, quercetin 3-O-p.coumaroyl-diglucoside ( $\mathrm{Rt}=37$ ), quercetin 3-O-P.coumaroyl-glucoside $(\mathrm{Rt}=40.5)$, quercetin $(R t=41.5)$, kaempferol and its acylated derivative $(R t=47)$. Only non-acylated glycosides of quercetin and kaempferol contributed to chemical variations among different cultivars based on the results of PCA. Conclusion: The genus Begonia is very heterogeneous and it is possible to distinguish several chemotypes whose differences rely on the complementarities between the metabolic pathways involved in the biosynthesis of glycosides of quercetin and kaempferol. Key words: Begonia, Distribution, Chemotype, Flavonoids, HPLC.
\end{abstract}

\section{INTRODUCTION}

Begonias are used for decoration and aesthetic appearance; belong to the family Begoniaceae distributed throughout tropical and subtropical regions of the world particularly in South and Central America, Africa and South Asia. ${ }^{1,2}$

The bright and varied colors of plants always fascinated the man. These colors find their origin in chromatic properties of various pigments; flavonoid take an important place and are involved in coloring flowers, fruits and sometimes leaves. ${ }^{3}$ They are accumulated in the form of glycosides in the chloroplasts and the vacuoles, ${ }^{4}$ and confer various biological effects to plants, like stimulating pollen germination, ${ }^{5}$ protection against UV radiation ${ }^{6}$ and resistance to pathogenic organisms. ${ }^{7}$ On the other hand, these phenolic compounds have showed wide range of pharmacological activities including antioxidant, ${ }^{8}$ anti-inflammatory, ${ }^{9}$ antimicrobial, ${ }^{10,11}$ antihemorragic activities $^{12}$ and anticancer activity. ${ }^{13}$ In recent years, the study of the flavonoids took a great place in research studies due to the improvement of the extractive techniques and the progress of the methods of structural analysis. Hence, the present study intended to identify the flavonoids isolated from flowers and their distribution in different horticultural types of Begonia. These popular ornamental plants consist of herbs, shrubs and lianas cultivated for their beautiful flowers and decorative foliage. ${ }^{14,15}$

\section{MATERIALS AND METHODS}

\section{Plant material}

The study was conducted on floral material of 7 different horticultural types: bamboo Begonia, Begonia elatior, tuberous Begonia, bushy Begonia, frutescent Begonia, rhizomatous Begonia and failing Begonia. The major of these cultivars were maintained by vegetative propagation, cultivated in greenhouse at a temperature of $22^{\circ} \mathrm{C}$ and humidity of $75 \%$. The flowers of these cultivars were harvested at a stage corresponding to three opening days floral and stored in the freezer. The petals of the flowers were collected at the laboratory of Phytochemistry of the University Claude Bernard (Lyon I), France.

\section{Preparation of the extracts}

Two protocols were applied to prepare extracts of Begonia flowers:

The first extraction concerned 184 cultivars belonging to different horticultural types of Begonia. 20 petals of fresh flowers of each accession were macerated in $50 \mathrm{ml}$ of metha- 
nol-ethanol $(1: 1)$ at $80^{\circ} \mathrm{C}$ for $30 \mathrm{~min}$. The extract was recovered by filtration, evaporated to dryness under reduced pressure at $40{ }^{\circ} \mathrm{C}$ and then dissolved in $5 \mathrm{ml}$ of methanol. These extracts were submitted to high performance liquid chromatography (HPLC).

The second extraction was carried out on a mixture of frozen flowers from different horticultural types of Begonia. The floral material was extracted by maceration in methanol-ethanol $(1: 1)$, under reflux at $80^{\circ} \mathrm{C}$ for $30 \mathrm{~min} .{ }^{16}$ The mixture was then filtered and evaporated to dryness under reduced pressure. The dry residue was treated with $200 \mathrm{ml}$ of boiling distilled water to dissolve the flavonoids. This solution was left to settle in the refrigerator for $24 \mathrm{~h}$ and then filtered through Whatman filter paper. Phenolic compounds of this filtrate were extracted three times with ethyl acetate. The organic and aqueous phases $(\mathrm{E}$ and $\mathrm{H}$ ) obtained by this treatment were evaporated to dryness under reduced and then dissolved respectively with methanol and MAW (methanol/acetic acid/water, $4: 1: 5)$.

\section{Separation and purification of flavonoids from extracts of Begonia flowers \\ Column chromatography}

The extracts of Begonia flowers were fractionated by column chromatography using polyamide SC6 (Mackerey and Nagel). For the organic phase (E), the elution was started with toluene and decreasing the polarity in $5 \%$ with methanol to $100 \%$ methanol to yield 8 fractions (E1-E8). In another hand, the aqueous phase $(\mathrm{H})$ was eluted with a gradient of water/methanol with increasing percentage of methanol and yields 3 fractions (H1-H3). The progress of development was monitored with UV lamp.

\section{Thin layer chromatography (TLC)}

Fractions collected from column chromatography were submitted to preparative thin layer chromatography in order to estimate their phenolic composition and separate their components.

The glass plates $(20 \times 20 \mathrm{~cm})$ thinly coated with polyamide $\mathrm{DC}_{6}$ (Mackerey and Nagel) which was prepared by mixing $10 \mathrm{~g}$ of polyamide powder in $55 \mathrm{ml}$ of ethanol. $2-5 \mu \mathrm{l}$ of ethyl acetate and aqueous fractions were separately spotted on the plates. The chromatograms were developed solvent system: toluene/methanol/ methylethylketone (4:3:3). The developed plates were air dried and visualized under UV light at $365 \mathrm{~nm}$. Flavonoid bands were delimited, scraped off and extracted with methanol. The purity of the recovered compounds was established by TLC using a second solvent system: water/methanol/ methylethylketone/ acetyl acetone (13:3:3:1). Once isolated, the flavonoids were purified over Sephadex LH-20 column with methanol. The values of retention factor (Rf) were then determined under UV light at $365 \mathrm{~nm}$ using the following solvent systems:

- $\quad$ System 1: toluene/methanol/methylethylketone, 4:3:3

- System 2: water/methanol/methylethylketone/acetylacetone, 13:3:3:1

- System 3: acetic acid/water (15\%)

\section{High performance liquid chromatography (HPLC) analysis}

This assay was used to identify and quantify the levels of flavonoid in the different types of Begonia. For Begonia flavonoids, separation was carried out using a Kontron HPLC system 600 with diode array detector and a reverse phase column $\mathrm{C} 18$ (30 $\mathrm{cm}$ in length, $5 \mu \mathrm{m}$ particle size) proceeded by a C18 guard column which retain the impurities and coupled to a photodiode array detector. The mobile phase consisted of two solvents; solvent A: water-acetonitrile-acetic acid (90:10:4) and solvent B: water-acetonitrile-acetic acid (80:20:4).
Qualitative analysis was made in step gradient mode, with $2 \%$ to $40 \%$ of solvent $\mathrm{B} /$ solvent $\mathrm{A}$ in $60 \mathrm{~min}$ and $40 \%$ to $90 \%$ in $10 \mathrm{~min}$, at a flow-rate of $1 \mathrm{ml} / \mathrm{min} .20 \mu \mathrm{l}$ of extract of each cultivar or isolated flavonoids from Begonia flowers were injected and the acquisition of data was performed at $340 \mathrm{~nm}$.

The chromatographic profiles were recorded by identifying the peaks according to their retention time and each peak was quantified by its area expressed in a percentage.

\section{Structural identification of Begonia flavonoids}

The identification of the flavonoids was carried out by UV/Visible spectroscopy, hydrolysis method (acid and alkaline hydrolysis) and cochromatography with standards..$^{17,18}$

\section{UV spectroscopic analysis}

The pure flavonoids isolated from extracts of Begonia flowers by preparative chromatography were subjected to UV- spectroscopic analysis. For each sample, the spectra were measured at the wavelength ranging from $200-500 \mathrm{~nm}$ in methanol and in the presence of the classical shift reagents according to the method of Mabry, ${ }^{17}$ and Voirin. ${ }^{18}$

\section{Acid and alkaline hydrolysis \\ Acid hydrolysis}

The method consisted of heating the component which was suspected to be a glycoside, 15 to 120 min with $\mathrm{HCl}(2 \mathrm{~N})$ in a water bath and the mixture was then cooled. The aglycone extracted twice with ethyl ether, was identified by UV-spectroscopy and co-chromatography with authentic standards. ${ }^{19}$ The sugars remain in the aqueous phase, were identified by co-chromatography with standards (glucose, xylose, rhamnose, galactose and arabinose) on silica gel 60 F254 plates using acetone/water (90:10) as mobile phase. The revelation of the sugars is done by spraying the plates with aniline malonate, then heating in an oven at $100^{\circ} \mathrm{C}$.

\section{Alkaline hydrolysis}

The acylated flavonoid was mixed with solution of potassium hydroxide $\mathrm{KOH}(1 \mathrm{~N})$ in $10 \%$ of methanol during 30 min under nitrogen atmosphere. After acidification to $\mathrm{pH} \mathrm{3,} \mathrm{the} \mathrm{phenolic} \mathrm{acid} \mathrm{was} \mathrm{extracted} \mathrm{at}$ first with ether and the aglycone by ethyl acetate secondly. ${ }^{19}$ The phenolic acid and the aglycone were identified by UV spectroscopic analysis and co-chromatography with authentic standards. The released sugars underwent the same processing described previously in the acid hydrolysis.

\section{Statistical Analysis}

The HPLC data were subjected to principal component analysis (PCA) by ADE-3.1: Hyper-Card@ Stacks and QuickBasic Microsoft@; UCB Lyon 1, France.

\section{RESULTS AND DISCUSSION}

\section{Structure characterization of Begonia flavonoids by TLC and UV spectroscopy}

Separation of flavonoids of the ethyl acetate extract using column chromatography afforded 8 fractions (E1-E8) and aqueous extract yield 3 fractions (H1-H3). After evaluation of their phenolic content, only in the fractions E4, E5, E6 and $\mathrm{H} 2$ showed the presence of several compounds and allowed the isolation of several sub fractions combined into 10 compounds (C1-C10) on the basis of their UV spectra in methanol and $\mathrm{Rf}$ in the different solvent system cited above Table 1 . The TLC revealed the presence of yellow and violet spots corresponding respectively to aglycones $(\mathrm{C} 1, \mathrm{C} 2$, and $\mathrm{C} 6)$ and glycosides substituted at 3 -position. On the other hand, according to UV spectra data in methanol Table 1; the compounds isolated from Begonia flowers belong to flavonol types. ${ }^{20}$ 
Table 1: Spectral and chromatographic characteristics of compounds isolated from Begonia flowers.

\begin{tabular}{lccccccc} 
& Compounds & UV spectra & \multicolumn{3}{c}{ Rf in solvent system } & Fluorescence \\
& Band I Band II & \multicolumn{3}{c}{$\begin{array}{c}\text { 1 } \\
\text { 2 }\end{array}$} & $\mathbf{3}$ & \\
\hline C1 (E4a) & 266 & 366 & 0.42 & 0.00 & 0.03 & yellow \\
C2 (E5a2) & 266 & 365 & 0.26 & 0.00 & 0.02 & yellow \\
C3 (E4b2=E5c2=E5b2) & 266 & 349 & 0.25 & 0.15 & 0.35 & violet \\
C4 (H2b) & 266 & 350 & 0.23 & 0.28 & 0.54 & violet \\
C5 (E5d2) & 266 & 349 & 0.08 & 0.28 & 0.54 & violet \\
C6 (E5a1=E6a) & 255 & 371 & 0.24 & 0.00 & 0.02 & yellow \\
C7 (E4b1=E5b1=E5c1=E6d2) & 256 & 355 & 0.14 & 0.15 & 0.28 & violet \\
C8 (H2a=E5d1=E6f) & 257 & 358 & 0.12 & 0.30 & 0.49 & violet \\
C9 (E6b) & 257 & 358 & 0.16 & 0.00 & 0.27 & violet \\
C10 (E6d1) & 257 & 360 & 0.09 & 0.15 & 0.48 & violet \\
\hline
\end{tabular}

The UV spectra and the data of acid hydrolysis are shown below. These results agreed with those reported for known compounds.

\section{Compound C1}

The UV spectra of compound I obtained in this study were as follows: $\mathrm{UV} \lambda \mathrm{MeOH} \max (\mathrm{nm}) 266,365 ;+\mathrm{NaOH} 277,317,413 ;+\mathrm{AlCl}_{3} 269,351$, $424 ;+\mathrm{AlCl}_{3} / \mathrm{HCl} 269,349,424 ;+\mathrm{NaOAc} 274,483 ;+\mathrm{NaOAc} / \mathrm{H}_{3} \mathrm{BO}_{3} 261$, 365. The co-chromatography of this product with authentic standards showed the same Rf with kaempferol in the solvent systems 1, 2 and 3. Based on the above data, compound C1 was identified as Kaempferol.

\section{Compound C2}

UV $\lambda \mathrm{MeOH} \max (\mathrm{nm}) 266,365 ;+\mathrm{NaOH} 277,317,413 ;+\mathrm{AlCl}_{3} 269$, 351,$424 ;+\mathrm{AlCl}_{3} / \mathrm{HCl} 269,349,424 ;+\mathrm{NaOAc} 274,483 ;+\mathrm{NaOAc} / \mathrm{H}_{3} \mathrm{BO}_{3}$ 261,365 . All the properties of this compound were similar of those of the compound $\mathrm{C} 1$, except for its $\mathrm{Rf}$ which was different in the solvent system 1. This suggested that this aglycone was acylated. The kaempferol was liberated by alkaline hydrolysis but the phenolic acid has not been identified when subjected to co-chromatography with standards. The small amount of this compound was not sufficient to allow further analyzes.

\section{Compound C3}

UV $\lambda \mathrm{MeOH} \max (\mathrm{nm}) 266,349 ;+\mathrm{NaOH} 274,326,401 ;+\mathrm{AlCl}_{3} 274$ $303,350,394 ;+\mathrm{AlCl}_{3} / \mathrm{HCl} 275,303,347,396 ;+\mathrm{NaOAc} 274,304,382$; $+\mathrm{NaOAc} / \mathrm{H}_{3} \mathrm{BO}_{3} 268,299,359$.

The mean values of $\mathrm{Rf}$ in the system solvent 2 and 3 are similar to a monosaccharide derivative. The acid hydrolysis released kaempferol and glucose. Hence, this compound was characterized as Kaempferol 3-O-glucoside.

\section{Compound C4}

UV $\lambda \mathrm{MeOH} \max (\mathrm{nm}) 266,350 ;+\mathrm{NaOH} 274,327,401 ;+\mathrm{AlCl}_{3} 274$, $304,352,398 ;+\mathrm{AlCl}_{3} / \mathrm{HCl} 274,302,349,398 ;+\mathrm{NaOAc} 274,303,388$; $+\mathrm{NaOAc} / \mathrm{H}_{3} \mathrm{BO}_{3} 268,362$. It was characterized by an $\mathrm{Rf}$ similar to that of rutin in the solvent system which showed that it is a disaccharide. The acid hydrolysis of this compound released kaempferol, rhamnose and glucose. These data suggested that compound C4 was Kaempferol 3-O-glucosyl-rhamnoside.

\section{Compound C5}

UV $\lambda \mathrm{MeOH} \max (\mathrm{nm}) 266,349 ;+\mathrm{NaOH} 281,326,402 ;+\mathrm{AlCl}_{3} 274$, $304,352,399 ;+\mathrm{AlCl}_{3} / \mathrm{HCl} 269,302,347,397 ;+\mathrm{NaOAc} 274,305,379$; $+\mathrm{NaOAc} / \mathrm{H}_{3} \mathrm{BO}_{3} 268,301,359$.

It has the same chromatographic behavior in the solvent systems 2 and 3 to that of the compound 4 , but different in the system 1 . What suggests that it is an acylated kaempferol. The alkaline hydrolysis of C5 released kaempferol, rhamnose and glucose; but did not allow the identification of phenolic acid. The small amount of this compound was not sufficient to allow further analyzes.

\section{Compound C6}

$\mathrm{UV} \lambda \mathrm{MeOH} \max (\mathrm{nm}) 255,302,371 ;+\mathrm{NaOH} 290,326,426 ;+\mathrm{AlCl}_{3} 271$, 299, 349; $+\mathrm{AlCl}_{3} / \mathrm{HCl} 266,262,429 ;+\mathrm{NaOAc} 274,323,386 ;+\mathrm{NaOAc} /$ $\mathrm{H}_{3} \mathrm{BO}_{3} 260,388$. These spectral data coincided with those of quercetin. It was characterized either by an Rf similar to the quercetin. The identified structure was Quercetin.

\section{Compound C7}

UV $\lambda \mathrm{MeOH} \max (\mathrm{nm}) 256,355 ;+\mathrm{NaOH} 272,330,408 ;+\mathrm{AlCl}_{3} 274$, $427 ;+\mathrm{AlCl}_{3} / \mathrm{HCl} 269,298,360,401 ;+\mathrm{NaOAc} 273,325,389 ;+\mathrm{NaOAc} /$ $\mathrm{H}_{3} \mathrm{BO}_{3} 264,301,381$.

This product had mean values of the Rf in the solvent system 2 and 3, which are in favor of a monosaccharide derivative. Quercetin and glucose were obtained after acid hydrolysis of C7. Hence, this compound was identified as Quercetin 3-O-glucoside (isoquercitrin).

\section{Compound C8}

UV $\lambda \mathrm{MeOH} \max (\mathrm{nm})$ 257, 358; + $\mathrm{NaOH} 272,329,411 ;+\mathrm{AlCl}_{3} 273$, $419 ;+\mathrm{AlCl}_{3} / \mathrm{HCl} 263,298,366,406 ;+\mathrm{NaOAc} 273,324,406 ;+\mathrm{NaOAc} /$ $\mathrm{H}_{3} \mathrm{BO}_{3} 264,384$. These spectral data coincided with those of rutin. The co-chromatography of this compound with authentic standards showed similar Rf to that of the rutin in the solvent systems 1, 2 and 3. Quercetin, rhamnose and glucose were obtained by acid hydrolysis of C8. This allowed proposing the structure of Quercetin 3-O-glucosyl-rhamnoside (rutin).

\section{Compound C9}

UV $\lambda \mathrm{MeOH} \max (\mathrm{nm}) 257,268,358 ;+\mathrm{NaOH} 272,368,414 ;+\mathrm{AlCl}_{3}$ $273,307,427 ;+\mathrm{AlCl}_{3} / \mathrm{HCl} 269,301,401 ;+\mathrm{NaOAc} 273,314,380$ $+\mathrm{NaOAc} / \mathrm{H}_{3} \mathrm{BO}_{3} 263,313,378$. It was characterized by an Rf similar to that of Quercetin 3-O-glucoside in the solvent system 1 and 3, but did not migrate in the system 2 . This is due to the presence of a phenolic acid. The resulting hydrolysates from the alkaline hydrolysis corresponded to quercetin, glucose and p-coumaric acid. This compound was identified as Quercetin 3-O-p-coumaroyl-glucoside.

\section{Compound $\mathrm{C} 10$}

UV $\lambda \mathrm{MeOH} \max (\mathrm{nm}) 257,266,316,360 ;+\mathrm{NaOH} 271,312,373$; $+\mathrm{AlCl}_{3} 274,301,412 ;+\mathrm{AlCl}_{3} / \mathrm{HCl} 273,301,400 ;+\mathrm{NaOAc} 273,314,388$; $+\mathrm{NaOAc} / \mathrm{H}_{3} \mathrm{BO}_{3} 263,313,378$. It was characterized by a similar $\mathrm{Rf}$ to that 
of the rutin in the solvent system 3 , but different in systems 1 and 2 . This is due to the presence of a phenolic acid. The products resulting from the alkaline hydrolysis corresponded to quercetin, glucose and p-coumaric acid. Thus, the correspondent molecule was Quercetin 3-O-p-coumaroyl-diglucoside.

Of these identified flavonols of Begonia flowers, quercetin, quercetin 3-O-rutinoside (rutin), quercetin 3-O-glucose (isoquercitrin) and kaempferol 3-O-glucoside were isolated from Begonia glabra and Begonia fagifolia, ${ }^{21,22}$ Begonia erytrophylla, ${ }^{23}$ Begonia formosana and Begonia fanic, ${ }^{24}$ and Begonia grandis. ${ }^{25}$ The other compounds are reported for the first time.

\section{Confirmation of the structure of flavonoids isolated from Begonia flowers by reversed-phase HPLC}

The data provided by the conventional methods (chromatography and UV spectrometry) were supplemented by reversed-phase HPLC analysis. The optimized HPLC conditions led to a good separation of 25 peaks assigned based on their retention time Figure 1 and quantified in per cent by integration of their area. Eight of them were identified by comparing their retention time ( $\mathrm{Rt}$ in $\mathrm{mn}$ ) to that of the isolated compounds (C1-C10) characterized previously on the basis of their chromatographic and spectral properties. The peaks 9, 10, 14, 15, 19, 21,22 and 25 corresponded respectively to quercetin 3-O-glucosylrhamnoside $(\mathrm{Rt}=23.5)$, quercetin 3-O-glucoside $(\mathrm{R} t=25)$, kaempferol 3-O-glucosyl-rhamnoside and its acylated derivative ( $\mathrm{Rt}=32)$, kaempferol 3-O-glucoside ( $\mathrm{Rt}=33$ ), quercétine 3-O p.coumaroyl-diglucoside ( $\mathrm{R}=37)$, quercétine 3-O-P.coumaroyl-glucoside ( $\mathrm{R}=40.5)$, quercetin $(\mathrm{R} t=41.5)$, kaempferol and its acylated derivative $(\mathrm{R} t=47)$. The remaining peaks are unidentified molecules which have not been isolated by preparative chromatography because of their low amounts.

\section{Principal component analysis (PCA) of 184 cultivars of Begonia}

The Principal Component Analysis (PCA) analysis of HPLC data of 184 Begonia cultivars showed that the two principal components (F1 and F2) accounted for $68 \%$ of the total variance and was highly significant. As shown in Figure 2, of 25 variables analyzed, the main compounds

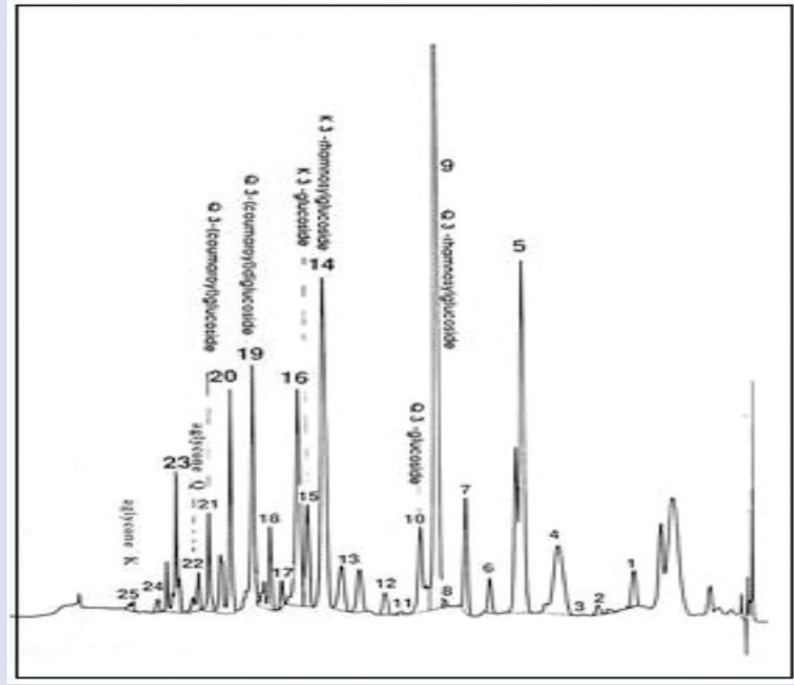

Figure 1: HPLC chromatogram of extract of Begonia flowers. Q: quercetin, K: kaempferol.

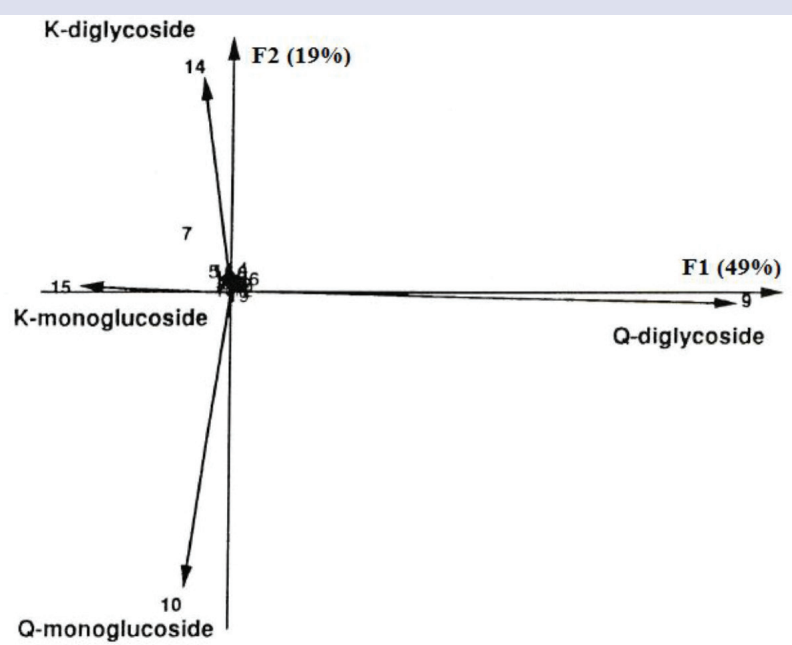

Figure 2: Principal Component Analysis of HPLC data of 184 of Begonia cultivars and score plot of 25 variables on the F1 x F2 factorial plane.

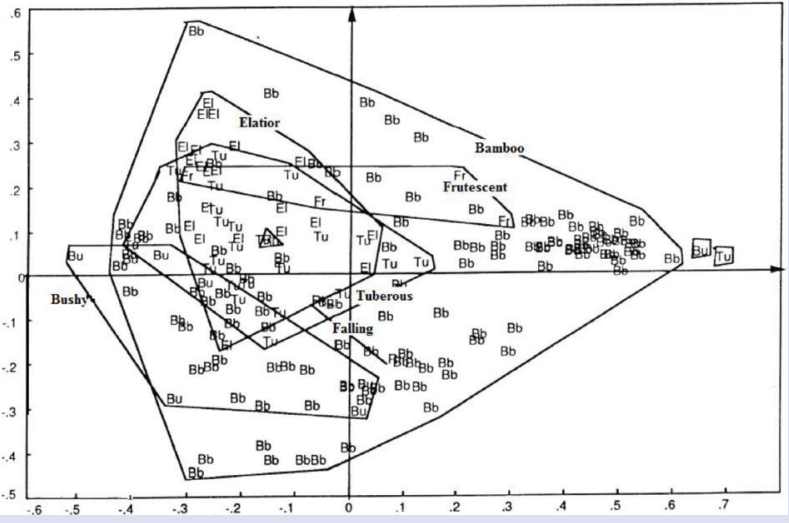

Figure 3: Distribution of flavonoids composition data into 184 cultivars of Begonia.

contributing in varietal discrimination were glycosides (mono and diglycoside) of kaempferol and quercetin. In the first principal component F1 which explained $49 \%$ of the total variance was positively correlated with the variable 9 (quercetin 3-O-glucosyl-rhamnoside) and negatively correlated to variable 15 (Kaempferol 3-O-glycoside). However, the second principal component F2 (19\% of the total variance) was positively correlated with variable 14 (kaempferol 3-O-glycosyl-rhamnoside) and negatively correlated with the variable 10 (quercetin 3-O-glycoside). The other flavonoids were not significant to contribute to varietal discrimination, due to their low content.

The Figure 3 illustrated the distribution of the cultivars of the different horticultural types based on their coordinates in the two-dimensional space and exhibited great flavonoid variability.

\section{Distribution of flavonoids into 120 cultivars of bamboo Begonia}

As shown in the Figure 3, the bamboo Begonia varieties distributed on the right of axis 1 were characterized by high content of quercetin 3-O-glucosyl-rhamnoside and low level of Kaempferol 3-O-glycoside. The other varieties located in the neighbor of axis 2 were characterized by 
the presence of quercetin 3-O-glucosyl-rhamnoside (9) and kaempferol 3-O-glycosyl-rhamnoside (14) or quercetin 3-O-glucosyl-rhamnoside (9) and quercetin 3-O-glycoside (10). The varieties with higher contents of the Kaempferol 3-O-glycoside (15) were located in the negative part of the axis 2 , and were differentiated by the presence of quercetin 3-O-glycoside (10) and kaempferol 3-O-glycosyl-rhamnoside (14). According to their flavonol profile, the varieties of this type could be divided into five clusters designated by chemotypes A, B, C, D and E characterized by their richness in compounds 9 and 15, 9 and 14, 9 and 10, 15 and 14 or 15 and 10 respectively.

\section{Distribution of flavonoids into 64 cultivars of the other horticultural types of Begonia}

The distribution of the 64 varieties by their coordinates in the two-dimensional space was represented by Figure 3 which highlighted similarities and differences between the varieties as follows:

The data obtained with the elatior and tuberous types are superposed. This is in agreement with the hypothesis that elatior varieties originate from a cross between tuberous hybrids. ${ }^{26}$ The varieties of Begonia elatior were clustered along the axis 2 and those of the tuberous type along the axis 1 . On the negative part of these two axes, the cultivars of these horticultural types were characterized by the presence of kaempferol derivatives (14 and 15); and those distributed on the positive part of axis 1 possessed high level of quercetin 3-O-glucosyl-rhamnoside (9) and glycoside 10 or 14 . The unidentified compound 7 was specific to elatior and tuberous types, which differentiate them from the other horticultural types.

Although, these two types are morphologically different, they possess complementary biosynthetic pathways of the heterosides 9 and 14 (chemotype B), 9 and 10 (chemotype C) or 15 and 14 (chemotype D). The frutescent cultivars are homogeneous and are rich exclusively in heterosides 9 and 14 (chemotype B). This differentiated them from varieties of the bushy type characterized by high contents of glycosides 9 and 10 (chemotype C) or 15 and 10 (chemotype D).

The rhizomatous type has two major glycosides 9 and 10 (chemotype D).

\section{CONCLUSION}

The phytochemical study of flavonoids Begonia flowers showed that the main components were determined as flavonol type corresponding to quercetin and kaempferol aglycones or glycosides (mono and diglycoside), acylated and non-acylated components. The acyl was identified as a p-coumaric acid. Among these flavonols, 6 molecules are reported for the first time in this genus. On the other hand, the evaluation of the flavonol composition by reversed-phase HPLC showed a significant variation of flavonoid content between different types of Begonia. The Principal Component Analysis (PCA) of HPLC data indicated that the non-acylated glycoside of quercetin and kaempferol summarize the essential flavonoid variability which is also important within the cultivars of the same type as between distinct types. This heterogeneity is due to an antagonism between the glycosides (mono and diglycoside) of quercetin and kaempferol, resulting probably from different processes that regulate their metabolic pathways. Hence, the genus Begonia is very heterogeneous and it is possible to distinguish several chemotypes whose differences rely on the complementarities between the metabolic pathways involved in the biosynthesis of glycosides of quercetin and kaempferol.

The phenolic profiles of different varieties of Begonia could be used to create new cultivars by breeding, mutation or genetic engineering to modify flower color as reported for chrysanthemum, ${ }^{27}$ petunia ${ }^{28}$ and gerbera. ${ }^{29}$ In addition to their decorative value, cultivars which contained the highest amounts of quercetin and kaempferol glycosides could be selected as potential pharmaceutical resources.

\section{ACKNOWLEDGEMENT}

The authors gratefully acknowledge Pr Maurice Jay and the whole team of the Laboratory of Phytochemistry at University Claude Bernard Lyon I, for providing the necessary research facilities to carry on this study.

\section{CONFLICT OF INTEREST}

The authors have no conflict of interest.

\section{ABBREVIATION USED}

AlCl3: aluminum chloride; $\mathbf{H}_{3} \mathbf{B O}$ : boric acid; $\mathbf{H C l}$ : hydrochloric acid; HPLC: high performance liquid chromatography; KOH: potassium hydroxide; MeOH: methanol; $\mu$ l: micro-liter; NaOAc: sodium acetate; $\mathbf{N a O H}$ : sodium hydroxide; nm: nanometer; PCA: principal component analysis; Rf: retention factor; Rt: retention time; TLC: thin layer chromatography; UV: ultraviolet.

\section{REFERENCES}

1. Sands MJ. The Begonias of New Guinea- an overview. Blumea. 2009;54(1-1): 272-7.

2. Stults DZ, Axsmith BJ. First Macrofossil Record of Begonia (Begoniaceae). American Journal of Botany. 2011;98(1):150-3.

3. Bruneton J. Pharmacognosie-Phytochimie, plantes médicinales. 4ème édition, Tec \& Doc, Lavoisier. Paris; 2009.

4. Tanaka Y, Sasaki N, Ohmiya A. Biosynthesis of plant pigments: anthocyanins, betalains and carotenoids

5. The plant journals. 2008;54(4):733-49. 5- Peggy EP, Thomas $V$, Yinyuan $M$, Loveline PT. Chalcone synthase and flavonol accumulation in stigmas and anthers of Petunia hybrida. Plant Physiology. 1992;102(3):925-32

6. Neill SO, Gould KS. Anthocyanins in leaves: light attenuators or antioxidants. Functional Plant Biology 2003;30(8):865-73.

7. Mierziak J, Kostyn K, Kulma A. Flavonoids as important molecules of plant interactions with the environment. Molecules. 2014;19(10):16240-65

8. Sofna DS Banjarnahor, Nina Artanti. Antioxidant properties of flavonoids. Medical Journal of Indonesia. 2014;23(4):239-44

9. De Medina F, Sanchez F, Posadas O, Lopez R, Romero-Calvo C, Mascaraque G, et al. The intestinal anti-inflammatory activity of the flavonoid rutin requires oral administration and may involve effects on mucosal lymphocytes. Clinical Nutrition Supplements 2009:49.

10. Saffidine K, Sahli F, Zerroug MH. Antioxidant and antimicrobial activities of plantago major. International Journal of Pharmacy and Pharmaceutical Sciences. 2015;7(5):58-64.

11. Divya N, Thenmozhi S, Sureshkumar BT, Selvan M. Antibacterial activity of medicinal plant against wound infected pathogens. International Journal of Pharmaceutical Sciences and Research. 2014;5(11):4942-7.

12. Liu $H$, Zhang $L$, Lu S. Evaluation of antioxidant and immunity activities of quercetin in isoproterenol-treated rats. Molecules. 2012;17(4):4281-91.

13. Lowe HIC, Toyang NJ, Watson CT, Ayeah KN, Bryant J. HLBT-100: a highly potent anti-cancer flavanone from Tillandsia recurvata L. Cancer Cell Int. 2017;17(1):38.

14. Zhang KM, Yu HJ, Shi K, Zhou YH, Yu JQ, Xia XJ. Photoprotective roles of anthocyanins in Begonia semperflorens. Plant Science. 2010;179(3):202-8.

15. Lim TK. Edible medicinal and non-medicinal plants. Flowers. Vol. 7 and 8 Springer Science + Business Media. Dordrecht. 2014.

16. Chirol N, Jay M. Acylated anthocyanins from flowers of Begonia. Phytochemistry. 1995;40(1):275-7.

17. Mabry TJ, Markham KR, Thomas MB. The systematic identification of flavonoids. Springer-Verlag Ed. New York. 1970

18. Voirin B. UV spectral differentiation of 5-hydroxy- and 5-hydroxy-3-methoxyflavones with mono- $\left(4^{\prime}\right)$, di- $\left(3^{\prime}, 4^{\prime}\right)$ or tri- $\left(3^{\prime}, 4^{\prime}, 5^{\prime}\right)$-substituted $B$ rings. Phytochemistry. 1983;22(10):2107-45

19. Markham K.R. Techniques of flavonoid identification. Ed. Academic Press. London; 1982

20. Harborne JB, Williams CA. 2000. Advances in flavonoid research since Phytochemistry. 1992;55(6):481-504.

21. Ensemeyer M, Langhammer L. Two lipophilic flavonoids from Begonia glabra. Planta Medica. 1982;46(2):254-5.

22. Ensemeyer $M$ and Langhammer L. Begoniaceae. V: Phytochemical investigation of Begonia fagifolia Fischer. Arch. Pharm. 1984;317(8):692-5. 
23. Vereskovskii VV, Gorlenko SV, Kuznetsova ZP, DovnarTV. Flavonoids of the leaves of Begonia erythrophylla I. Chemistry of Natural Compounds. 1987;23(4):505

24. Iwashina T, Saito Y, Peng Cl, Yokota M, Kokubugatai G. Foliar Flavonoids from Two Begonia Species in Japan. Bulletin of the National Museum of Nature and Science Series B. 2008;34(4):175-81.

25. Karpova EA, Fershalova TD, Petruk AA. Flavonoids in Adaptation of Begonia grandis Dryander subsp. grandis introduced in West Siberia (Novosibirsk). Journal of Stress Physiology and Biochemistry. 2016;12(3):44-56

26. Georget P. Floriculture. Ed. SPES Lausanne-Dunod. Paris; 1966.

27. Courtney-Gutterson N, Napoli C, Lemieux C, Morgan A, Firoozabady E,
Robinson KE. Modification of flower color in florist's chrysanthemum: production of a white-flowering variety through molecular genetics. Biotechnology (NY). 1994;12(3):268-71.

28. Delange P, Van Blokland R, Kooter JM, Mol JN. Suppression of flavonoid flower pigmentation genes in Petunia hybrida by the introduction of antisense and sense genes. Curr Top Microbiol Immunol. 1995;197:57-75.

29. Elomaa P, Helariutta $Y$, Kotilainen M, Teeri TH. Transformation of antisense constructs of the chalcone synthase gene superfamily into Gerbera hybrida: differential effect on the expression of family members. Molecular Breeding $1996 ; 2(1): 41-50$

\section{GRAPHICAL ABSTRACT}

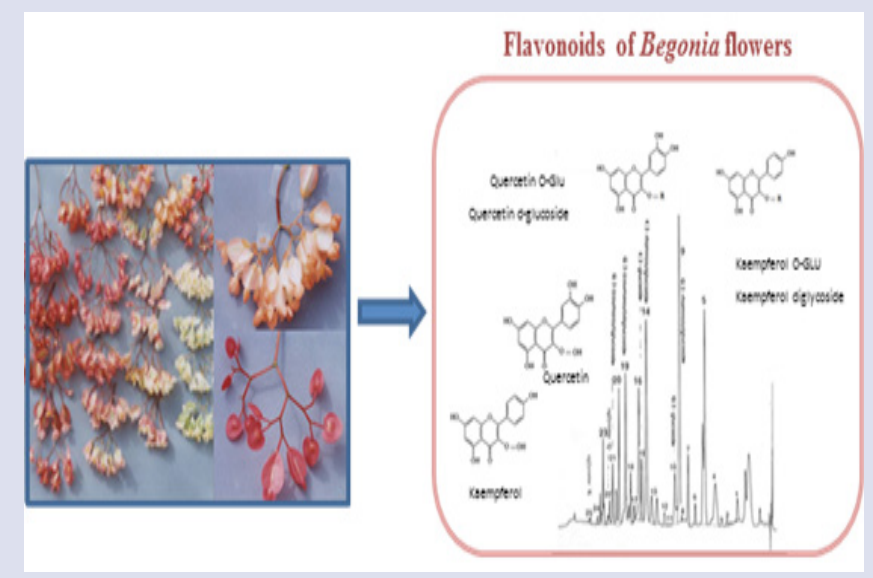

\section{SUMMARY}

- The phytochemical study was conducted on the flower extracts of different horticultural types of Begonia and leads to the isolation of 10 compounds corresponding to kaempferol and quercetin aglycones or glycosides (mono and diglycoside), acylated and non-acylated components. Six of these molecules are cited for the first time in this genus. On the other hand, the evaluation of the flavonol composition in different cultivars showed that glycosides (mono and diglycoside) of kaempferol and quercetin are the main compounds contributing in varietal discrimination.

- The genus Begonia is very heterogeneous and it is possible to distinguish several chemotypes within the cultivars of the same type as between distinct types. These differences rely on the complementarities between the metabolic pathways involved in the biosynthesis of glycosides of quercetin and kaempferol.

\section{ABOUT AUTHORS}

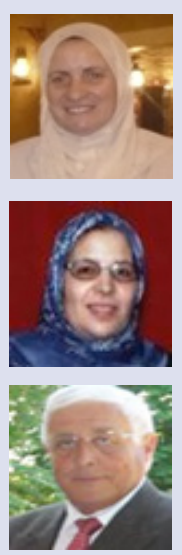

Dr Saffidine Karima: Department of Medicine, Faculty of Medicine, University Ferhat Abbas Setif1, Algeria.

Prof. Benayache Fadila: Molécules Bioactives, Analyses Physicochimiques et Biologiques (VARENBIOMOL), University Frères Mentouri - Constantine, Algeria.

Prof. Jay Maurice: he was professor head of Laboratory of phytochemistry, University Claude Bernard-Lyon I, Villeurbane, France. Actually, he is Vice-President Europe at World Federation of Rose Societies (WFRS).

Dr. Chirol Nadine: Laboratory of phytochemistry, University Claude Bernard-Lyon I, Villeurbane, France.

Cite this article: Karima S, Nadine C, Fadila B, Maurice J. Characterization and Distribution of Flavonoids from Flowers in Different Horticultural Types of Begonia. Pharmacog J. 2017;9(6):850-5. 